\title{
Negative aspects of counter-knowledge on absorptive capacity and human capital
}

Juan-Gabriel Cegarra-Navarro (Economía de la Empresa, Universidad Politécnica de Cartagena, Cartagena, Spain) Gabriel Cepeda Carrión (Administración de Empresas y Marketing, Universidad de Sevilla, Sevilla, Spain) Anthony Wensley (Institute of Communications, Culture, Information and Technology, The University of Toronto, Toronto, Canada)

\section{Abstract}

Purpose - People live and work in a world where they do not have complete knowledge and, as a result, they make use of rumours, beliefs and assumptions about relevant areas of concern. The term counter-knowledge has been used to refer to knowledge created from unverified sources. The purpose of this paper is to examine the relationship between counter-knowledge and human capital (HC) as well as investigating interactions between absorptive capacity (ACAP) and HC. Design/methodology/approach - A model is tested to examine the relationship between counter-knowledge, $\mathrm{HC}$ and the financial performance of 112 companies listed on the Spanish Stock Exchange. Findings - The results are calculated using structural equation modelling. This leads to the main conclusion that while the increasing presence of counter-knowledge leads to a reduction of ACAP and, by extension with HC. However, in the context of the sample, HC has positive effects on firms' performance. Therefore, consideration must be given to the evaluation of the real cost of counter-knowledge or inappropriate assumptions on HC. Practical implications - The key managerial implication of this paper is that management should actively develop an organizational culture which questions the source of any knowledge and favours evidence-based reasoning over reasoning based on "gut instinct", what has worked in the past and reasoning based on rumours and gossip. Originality/value - This paper provides empirical support for the argument that the all so-called "knowledge" generated from the sharing of unverified news is not necessarily good knowledge. Rumours or gossip shared thanks to unverified sources are some examples that illustrate people possibility to create inappropriate or false beliefs via unsupported explanations and justifications.

Keywords: Financial performance; Human capital; Absorptive capacity; Knowledge transfer; Counterknowledge 


\section{Introduction}

Intellectual capital possesses intellectual attributes that can contribute value of an organization (Bontis, 1998). Some of such intellectual attributes include Human Capital (HC). HC can be defined as the stock of competencies, knowledge, social and personality attributes, including creativity, embodied in the ability to perform human labor so as to produce economic value (Bogdanowicz \& Bailey, 2002). In the last decade and a half there has been a dramatic increase in interest in the concept of "human capital" and whether it produces any firm or industry effects on financial performance (Cheng et al, 2010). As Unger et al. (2011) point out, human capital increases employees' capabilities of discovering and exploiting business opportunities as well as these intellectual attributes help organizational members to identify and acquire other useful beneficial resources such as related knowledge. These ideas illustrate that, in order to create human capital, organizations need to build an overall picture of the learned knowledge with a considerable degree of familiarity (Nahapiet \& Ghoshal, 1998).

In this paper, we focus on the capacities that facilitate learning or the more rapid acquisition of knowledge. The concept of absorptive capacity has been increasingly drawn on by researchers to explain the transformation of external knowledge into innovations (e.g. Gray, 2006; Noblet et at., 2011). Absorptive capacity (ACAP) can be conceptualized as a set of organizational abilities to manage knowledge, assimilate it, and apply it to commercial ends (Cohen \& Levinthal. 1990). Kim (1998) understands absorptive capacity as skills relating to the ability to learn and solve problems that enable a firm to assimilate knowledge and create new knowledge. It should be noted here that knowledge is placed 
in an intellectual capital context as soon as it is recognized as capital or resource (Andriessen, 2006) and ACAP plays an important role in the acquisition, assimilation, transformation and exploitation of external knowledge in an organization by, for example, facilitating a friendly environment where collective knowledge can grow (Zhou \& Fink, 2003).

Counter-knowledge in contrast to scientific knowledge, often masquerades as scientific knowledge but, in contrast, can be shown to be untrue with reference to known facts or shown to lack appropriate supporting evidence. Indeed, the very lack of supporting evidence for counter-knowledge may be used as evidence of the truth of a particular statement - for example the statement that a cure for cancer exists leading to the suppression of all positive evidence (Thompson, 2008). Rumours, gossip, unsupportable explanations and justifications, and inappropriate or false beliefs are just some of the examples that illustrate an organisation's employees' capacity to create and share counter-knowledge. The creation of counter-knowledge occurs when an individual or individuals create inappropriate or false interpretations of events or sequences of events. This counter-knowledge leads individuals to develop world-views that are distorted and at most partially true.

We propose that the existence of counter-knowledge will influence ACAP and, by extension, human capital (HC) as organizational members share inappropriate assumptions about inappropriate routines or utilize inappropriate approaches to scanning the wider business environment and, also, to defining, meeting and bringing forward their ideas by introducing new knowledge structures (Gibb, 1997). In other words, counter-knowledge can influence ACAP and HC because managers and 
organizational members perceive and follow knowledge structures which arise from rumours and outdated routines or procedures and, more generally, counter-knowledge.

There is a lack of empirical evidence, particularly in relation to the Spanish companies listed on the Spanish Stock Exchange that can be used to investigate the relationship between ACAP and the existence or non-existence of $\mathrm{HC}$, or to the impact of $\mathrm{HC}$ on financial performance. We also investigate whether counter-knowledge has an effect on ACAP and HC. This paper addresses the following questions "What is the nature and strength of the relationship between the existence of counter-knowledge and ACAP?" and "What part does the concept of counter-knowledge play?". These relationships are examined through an empirical investigation of 112 companies listed on the Spanish Stock Exchange. The theoretical framework is proposed in the next section of our paper. Details of the survey which was used to collect appropriate data to test the model is presented in section 3 and the results of testing the models are presented in section 4 . The results and managerial implications are discussed in section 5 which is followed by our general conclusions in section 6 .

\section{The proposed research model}

Intellectual capital term was first introduced by Galbraith (1969), he suggests that intellectual capital is not only a set of fixed assets but also the organizational processes that are in place to achieve organizational objectives. Intellectual capital can thus include the skills and knowledge that a firm has accumulated about how to create its goods or services (Bogdanowicz \& Bailey, 2002); the knowledge of individual employees or groups of employees that is likely to be critical to a company's continued 
success (Herholdt, 2004); and documents about processes, customers, research results, and other information that is likely to be valuable to the company and thus might have value for a competitor when such knowledge is not common knowledge (Abeysekera, 2006).

A significant number of scholars identify three main components of intellectual capital: human capital, structural capital and relational capital (e.g. Bueno, 1998; Mavridis \& Kyrmizoglou, 2005; Wall, 2007; Ruta, 2009; Maditinos et al, 2011). Human capital refers to knowledge, skills and experiences of individuals. Structural capital includes all non-human resources of knowledge in the organization which typically consists of databases, procedures and administrative processes, strategies and any knowledge that is the basis for the financial success and profitability of the organization. Finally relational capital comprises of knowledge relating to the creation and maintenance of relationships with customers (Chen et al, 2004).

This paper focuses on human capital, which may be the most valuable intangible asset (Weatherly et al, 2003), and the impact of counter-knowledge on an organization's human capital. Counter-knowledge may play an important role in the creation of human capital since the fact that before human capital can be created specific assumptions should be established and shared. An organisation will not be able to create human capital without this (Herholdt, 2004; Bogdanowicz \& Bailey, 2002; Abeysekera, 2006). In other words, human capital does not come into existence on its own (Galbraith, 1969) it comes into existence and is enriched through collective processes of knowledge combination and exchange (Nahapiet \& Ghoshal, 1998). 
One of the key factors affecting the extent and quality of a company's human capital is the degree to which it effectively exploits knowledge networks (i.e. cooperative relations between actors). Absorptive capacity (ACAP) develops and is enhanced as a result of both external connections and internal social networks. It utilizes an organization's internal experience, expertise, and processes in order to interpret the meaning of external knowledge and exploit it to improve organizational processes, goods and services, stimulate the innovative capacity of the organization and, generally, to improve the performance of the organization both operationally and strategically. The level of absorptive capacity is a function of the organization's existing resources, existing tacit and explicit knowledge, internal routines, management competences and culture (Gray, 2006). Zahra \& George (2002) have advanced our understanding of absorptive capacity by proposing the existence of two subsets of absorptive capacity namely potential and realized. While the term potential absorptive capacity (PACAP) is used to refer to the capacity to acquire and assimilate knowledge, the concept of realized absorptive capacity (RACAP) relates to transformational and exploitation capabilities with respect to knowledge.

The influence of counter-knowledge on entrepreneurial actions has been investigated by Cegarra, Eldridge and Wensley (2014). As we have noted counter-knowledge is of considerable importance, we live and work in a world where we do not have complete knowledge and, as a result, we make use of rumours, beliefs and assumptions about relevant areas of concern (Kurland \& Pelled, 2000). This observation is supported by Chapman and Ferfolja (2001) when they assert that gossip, rumours and malicious lies proliferate in the learning process and people can, as a result, be manipulated to learn and incorporate into their stock of knowledge items of 'counter-knowledge'. Thompson 
defines counter-knowledge as 'misinformation packaged to look like fact' (2008: p.1). Thompson further proposes that counter-knowledge is based on gossip, rumours and malicious lies and may lead to the adoption of inappropriate or outdated assumption. It has also been cogently argued that this counter-knowledge potentially leads to a degradation of organizational knowledge (Markoczy, 1994; Darr et al, 1995; Starbuck, 1996; Fernandez \& Sune, 2009).

Taking the foregoing into account and relating Thompson's definition (2008) to the work of Fernandez and Sune (2009), counter-knowledge can be viewed as resulting in a natural deterioration or depreciation of knowledge and knowledge structures, usually with negative consequences for learning processes, human capital, and, potentially organizational performance (Cegarra et al., 2014). For example, when organisational members provide information that is derived from rumour or gossip they help to undermine the learning process by providing counter-knowledge in place of knowledge (Cegarra et al, 2014).

The above considerations lead us to argue that individuals who tend to accept rumour and gossip may well develop an increased propensity to believe further rumours and gossip. For example, faced with a significant change in customer needs initially individuals may deny that these changes have really occurred and they may decide to rely completely on counter-knowledge that allows them to maintain their assumptions that customer needs have not changed. It is also important to note that such counterknowledge cannot be traced back to any original source. Over time they and their colleague may come to rely more on counter-knowledge rather than on consulting the customers directly. Indeed, the more counter-knowledge is used and assimilated the 
more likely it is that actual knowledge will be rejected as being inconsistent with the extensive counter-knowledge that has been assimilated. These considerations lead us to frame the first two hypotheses that we seek to test in our study:

Hypothesis 1: Counter-knowledge has a negative effect on absorptive capacity.

Hypothesis 2: Counter-knowledge has a negative effect on human capital.

Most prior studies of ACAP consider that ACAP facilitates the incorporation of new ideas by the organization, increases the capacity of organization members to understand new ideas and strengthens their creativity and enhances the ability to spot new opportunities (e.g. Chesbrough, 2003; Gray, 2006; Cepeda et al, 2012). Thus, ACAP can be identified as the key process in recognizing the value of new information by connecting previously unconnected ideas and knowledge or recombining previously connected knowledge in new ways (Jansen et al, 2008). The implementation of this process in turn provides a signal to the employees that they represent an important asset to the organization (Lin, 2007).

Taking into account all of the above, the development of ACAP can potentially increase the value of $\mathrm{HC}$ as a result of the acquisition of more relevant knowledge and skills and the avoidance of situations which might lead to emotional and motivational disruptions (Seligman \& Maier, 1967). When employees feel that the organization appears to be responsive to them as when it provides the right information at the right time, they tend to reciprocate with positive attitudes toward the organization, including the development of affective bonds and feelings of loyalty (Dutton et al, 1994). The 
development of positive attitudes typically leads to other more tangible benefits, such as reduction of absenteeism, lower stress levels, higher levels of productivity and performance and greater quality of life, satisfaction and commitment among employees (Nelson et al, 1990; Scandura \& Lankau, 1997). Consequently we propose the following hypothesis:

Hypothesis 3: Absorptive capacity has a positive effect on human capital.

Human capital has been recognized as a key factor for maintenance of company's positions and its improvement is linked to improved performance in both financial and non-financial dimension (Cheng et al, 2010). Specifically, Belkaoui’s research (2003), conducted in multinational US companies, showed that there is a significant positive relationship between the financial performance of U.S. multinational corporations and corporate intellectual capital. A possible explanation for these findings likely relates to the fact that human capital plays an important role in the improvement of financial performance through the suitable design and interpretation of appropriate financial measures. In addition, the better the human capital the better the ways in which the organization can be managed and challenging situations be appropriately resolved (Shane \& Venkatraman, 2000; Unger et al, 2011). Knowledge utilized by competent employees enables the organization to ensure that the organization can achieve its operational potential (Cheng et al, 2010). Hence we proposed the following hypothesis:

Hypothesis 4: Improvement of human capital will result in the company achieving improved financial performance 
Figure 1 illustrates our model. We assume that counter-knowledge has a negative influence on both ACAP and human capital. In our framework, it is also expected that intellectual capital be lead to the establishment of competitive advantage and hence to superior financial performance.

Insert Figure 1 about here

\section{Method}

\section{Data collection}

The population used in this study consists of Spanish organizations with more than 100 employees and companies that used the Editran tool in order to have a close financial relationships to their banks. Editran is a platform for communications over data networks and the internet allowing for the creation of advanced solutions that enable direct connectivity between IT applications in different computers and operating systems, in a heterogeneous environment of business activity, entities and public bodies. Editran's capacity to integrate with different operating systems, the dynamic configuration of its operating mode and simultaneous multiple exchanges with various remote centres and various network protocols have made Editran a key factor in electronic information exchange processes in the Spanish banking sector. Editran allows for the communication between large businesses and banks for the sending and receiving of transactions relating to salary payments, balances and transactions. 
Like other studies on this domain, this study was designed to cover a wide range of industries, but excluding the agricultural and construction sectors. 360 companies were identified from the SABI (Sistema de Análisis de Balances Ibéricos) database and invited to participate in the study. 121 companies agreed. Each company was also informed by telephone of the objectives of the research and they were assured their data would be processed both confidentially and anonymously. Telephone surveys were conducted over a period of 2 months, from October 2012 to November 2012. Before conducting the telephone surveys, senior managers from these companies were contacted and asked by our team to participate in the study. They were informed by telephone of the objectives of the research and they were assured of its strictly scientific and confidential character, as well as the global and anonymous treatment of the data.

A total of 112 valid and completed questionnaires were collected. Consequently, we had 112 complete telephone surveys giving a response rate of $33.61 \%$ of the total number of companies invited to participate, with a factor of error of $7.7 \%$ for $\mathrm{p}=\mathrm{q}=50 \%$ and a reliability level of $95.5 \%$. We note that the response rate exceeds the typical rate of between 10 to 25 percent which has been proposed as the average response rate for surveys involving senior management (Menon et al, 1996). Responding companies were compared with those that did not respond in terms of size and performance. No significant differences were found between these two groups, suggesting that there was no non-response bias.

\section{Measures}


Churchill's (1979) approach to questionnaire development was used, combining scales from several other relevant empirical studies with new items to make an initial list of 40 items (4 relating to counter-knowledge, 9 measuring PACAP, 12 measuring RACAP, 3 measuring $\mathrm{HC}$ and 4 relating to financial performance). Since specifying translation tasks require an exchange of information between researchers, questionnaire designers, target language implementers and translators (Acquadro et al., 1996), before undertaking the survey, a 60-minute (consensus, revision) meeting was held with an expert panel ( 3 potential responders, 1 item writer, 1 research team and the translator). The purpose of this meeting was to compare the independent translations of the same questionnaire and reconcile discrepancies and agree on a final version which taps the best of the independent translations (Guillemin et al., 1993). Based on this pilot study, several items were modified and the questionnaire constructs were operationalised and measured as follows (see Appendix for a list of items):

a) The counter-knowledge scale was constructed from a literature review and an expert panel in order to identify the appropriate items for this construct. Four items made up the scale for 'counter-knowledge'. Previous studies by Szvetelszky (2003) and Chapman \& Ferfolja (2001) provide guidance on how to develop items to measure counter-knowledge. Among the indicators of counter-knowledge, factors relating to the lack of congruity between the intended communication and its recipient (e.g. misunderstandings) are most often used (Thompson, 2008). We also adopted questions focusing on gossip which thrives on lies, exaggeration and partial truths (Chapman \& Ferfolja, 2001). In all cases responses were drawn from a 7-point Likert scale $(1=$ high disagreement and $7=$ high agreement). 
b) Potential and realised absorptive capacity (PACAP and RACAP). To examine potential and realised absorptive capacity, we sought to measure the dimensions that have been defined previously (Zahra \& George, 2002). Items were measured using a 7point Likert scale from the study by Jansen et al. (2005). PACAP consisted of two dimensions: acquisition and assimilation of new external knowledge. Six items assessed the intensity and direction of efforts expended in knowledge acquisition. In addition, four items measured the assimilation of knowledge and gauged the extent to which firms were able to analyze and understand new external knowledge. Ultimately, after the application of a data cleansing process, 5 and 3 items formed the acquisition and assimilation scales respectively. RACAP includes the transformation and exploitation of new external knowledge. Six items initially measured transformation and assessed the extent to which firms were able to facilitate recognition of the opportunities and consequences of new external knowledge for existing operations, structures, and strategies (Zahra \& George, 2002). Six items tapped into the extent to which firms were able to exploit new external knowledge. The scale gauged the ability of companies to incorporate new external knowledge into their operations. The final cleansed scale consists of 4 for transformation dimension and 3 items for exploitation dimension.

c) Human capital was measured by asking the managers to evaluate different questions focusing on specific characteristics of the company. We used the intellect model developed by Bueno (1998) consisting of the assessment of 3 items relating to human capital.

d) The initial measures relating to the nature of financial performance consisted of 3 items. Several measures of organizational performance have appeared in literature and 
we adopted the growth based measures proposed by McDougall et al. (1994), Roth and Ricks (1994), and Bontis et al. (2000) for ROI (Return on investments), ROE (Return on Equity) and profit margin (profitability). We used the SABI database to collect data of business results for the chosen companies from 2012.

\section{Data analysis}

In order to obtain a robust evaluation of the quality of the items, we carried out a confirmatory analysis (CFA), using the covariance matrix as input, via the EQS 6.1 robust maximum likelihood method (Bentler 1988). The CFA produced a good fit with an incremental fit index (IFI) of 0.97 and a comparative fit index (CFI) of 0.98 (also,

Satorra-Bentler $\left.\chi^{2}{ }_{(54)}=69.74 ; \chi^{2} / d . f=1.29 ; C F I=0.94 ; I F I=0.94 ; R M S E A=0.05\right)$. In all the measurements, Bagozzi and Yi's (1988) composite reliability index and Fornell and Larcker's (1981) average variance extracted index was higher than the evaluation criteria of 0.7 for composite reliability and 0.5 for the average variance extracted, as seen in Table 1.

Insert Table 1 here

We determined the discriminant validity by calculating the shared variance between pairs of constructs (the lower triangle of the matrix in Table 2) and verifying that the value was lower than the average variances extracted for the individual construct (the diagonals in Table 2). The shared variances between pairs of all possible scale combinations indicate that the variances extracted are higher than the associated shared variances in all cases (Fornell \& Larcker, 1981). In the interest of thorough discriminant 
validity, we carried out an additional test, which supports this assumption, since the confidence interval ( \pm 2 standard errors) around the estimated correlation between any two latent indicators never includes 1.0 (Anderson \& Gerbing, 1988).

\author{
Insert Table 2 here
}

\title{
Results
}

After checking the psychometric properties of the measures, the next step was to evaluate the relationships set out in our hypotheses $\mathrm{H} 1$ to $\mathrm{H} 4$. As seen in Table 3, the fit indices of the model are satisfactory (Satorra-Bentler $\chi^{2}{ }_{(50)}=56.76 ; \chi 2 / d . f=1.13$; $C F I=0.99 ; R M S E A=0.07$ ), suggesting that the nomological network of relationships fits the data -another indicator that supports the validity of these scales (Churchill 1979).

Insert Table 3 here

The results of hypothesis testing are presented in Table 4. As shown in Table 4, all our hypotheses were supported. We found a significant relationship between CK and ACAP explaining a 5 percent of the variance in ACAP. Counter-knowledge influences negatively, in the absorptive capacity of the firm. There is a negative and significant relationship between counter-knowledge and human capital. It seems the human capacities are distorted by counter-knowledge. Otherwise, ACAP is very close to the Intellectual capital, what supports our hypotheses 3 . With regards to $\mathrm{H} 4$, the relationship between human capital and financial performance was also supported. 
Insert Table 4 here

Finally, although our data is gathered from two different sources (firms and financial reports), common method bias might still influence some of the relationships formulated in our model. To rule out the existence of such a bias, we used methods suggested by Podsakoff et al., (2003), who recommend procedural remedies. We therefore applied these to protect respondent anonymity and reduce an apprension with respect to evaluation by assuring subjects that there were no right or wrong answers; to improve the scale items with a pre-test to a set of experts; and to counterbalance question order.

\section{Discussion}

The first contribution made by this research is the questioning of the existing models of the relationship between human capital and financial performance. In this paper, an integrative model provides positive theoretical views of human capital on objective performance measures. This confirms the position adopted by Bontis et al. (2000) when they argued that one of the most important contributors to the growth in organizations' output and financial performances. Thus, since human capital is not built in isolation but in interactive relationships, counteracting the negative effects of counter-knowledge is a necessary prerequisite for the building of human capital.

This research's second contribution is provided by the results of empirically testing the proposed hypotheses. This paper has examined the relationship between counter- 
knowledge and human capital and to represent these relationships in the model shown in Figure 1. The excellent fit of our model is a theoretically important finding since it means that counter-knowledge is a variable that will lead to negative effects on both ACAP and HC. We think that this is an important finding as mangers should not left uncontrolled counter-knowledge, the efforts to increase ACAP and $\mathrm{HC}$ in the organization would be weaker than they otherwise would be. The managerial implications of the relationships observed between the factors that constitute the conceptual framework shown in Figure 1 are discussed in more detail below.

With regard to $\mathrm{H} 1$ (counter-knowledge $\rightarrow A C A P$ ), the results support the position that ACAP is likely to suffer if the organizational culture does not adequately address counter-knowledge. A possible explanation for these findings may relate to the fact that counter-knowledge can provoke doubts with respect to recognize the value of new information, assimilate it, and apply it to commercial ends. For example, the reputation of a supplier may become affected by the malicious rumours from other competitors who have interacted with it. In these circumstances, counter-knowledge is an important trigger that contributes to a process of destabilization of the ACAP.

With regard to $\mathrm{H} 2$ (counter-knowledge $\rightarrow H C$ ), the results show a significant negative relationship between counter-knowledge and $\mathrm{HC}$, which means that counter-knowledge potentially leads to a reduction in the value of HC. A possible explanation would be the fact that counter-knowledge may impede the exchange of performance-enhancing information. As Labianca and Brass (2006) point out, individuals may feel confused and stressed at the prospect of being unable to rely on people who withhold critical information or provide bad references, which could lead to absenteeism and turnover. 
Furthermore, the acceptance of counter-knowledge in an organization may lead to the creation of a workplace that does not respect genuine knowledge and skills and therefore may lead to the most talented people quitting (Steven \& Roy-Girard, 2007).

The above considerations lead us to argue that when an organization confounds knowledge and counter-knowledge then the counter-knowledge be replaced with new knowledge and knowledge structures. Counter-knowledge limits individuals' prior knowledge of the potential interactions between new processes and their consequences, which in turn hinder their ability to plan, reason, and understand new situations effectively (Chapman \& Ferfolja, 2001). It is with this in mind that we propose that if managers are to take appropriate action having identified problems and mistakes, they need address the existence of counter-knowledge. One way of doing this would be for upper management to set up a committee to investigate specific rumours, gossip and unsupportable explanations. Furthermore, management should actively develop an organizational culture which questions the source of any knowledge and favors evidence-based reasoning over reasoning based on 'gut intinct', what has worked in the past and reasoning based on runour and gossip.

Regarding the test of hypothesis $\mathrm{H} 3(A C A P \rightarrow H C)$, our results support that ACAP is a prior step for enhancing HC. In this aspect, ACAP can be viewed as a way for improving learning corridors such as transformation capability and exploitation capability as this may involve a process of replacing existing counter-knowledge with new knowledge structures. ACAP enhance the effectiveness and efficiency of new knowledge which could lead to improved HC. 
With respect to the test of hypothesis $\mathrm{H} 4$ (HC $\rightarrow$ financial performance), the results support the position that, in order to improve financial performances, companies need to provide and support $\mathrm{HC}$ through the development of employee knowledge and knowledge acquisition, motivation and skills (i.e. HC). This also confirms the position adopted by Shane and Venkatraman (2000), when they argue that the enhancement of $\mathrm{HC}$ helps to increase the ability of employees to perform their day to day tasks of discovering and exploiting business opportunities, which in turn, positively impacts financial performance (Unger et al, 2011). Put another way, all ideas, decisions and processes in an organization rely on the input of the individual. It should be noted here that in this paper financial performances are measured using the "Sistema de Análisis de Balances Ibéricos" database (SABI) - the most complete database, which collects financial statement and profit and loss accounts of all the Spanish and Portuguese firms registered in the mercantile register. We think that this is an important finding, as it is based not only subjective measures to operationalise our constructs but also on objective measures.

The study has some limitations. The first limitation of this study is associated with the use of cross-sectional data. A potential limitation of cross-sectional data concerns the inability to specify the changes in measures over time. For example, counter-knowledge generated via rumors, gossip and malicious lies does not tend to be very long lasting. An individual's level of self-awareness can also be expected to change over time as new information and experiences are acquired through direct interaction with customers, performance feedback and other factors. As a result, the temporal ordering and causality cannot be definitively inferred from the results. Thus, longitudinal research is needed to conclusively replicate the findings presented here. Secondly, some factors which are 
also likely to affect the financial performances in other organizations have not been addressed in this study. These include, for example, of the level of organizational productivity and of the level of investment in human resources. Therefore, we consider that the use of additional information about these variables might help to better capture the richness of this construct. Finally, it would also be interesting to extend the survey to other countries because national or cultural issues might influence the way organisations accept and/or make use of counter-knowledge.

\section{Conclusions}

This paper analyzes the relationships between counter-knowledge and human capital and tries to identify whether human capital has an impact on the financial performance through an empirical study of 112 companies listed on the Spanish Stock Exchange. To sum up, we offer a model that integrates positive theoretical views of human capital on objective performance measures. Our results confirm that while counter-knowledge is a variable that is negatively associated with absorptive capacity and, by extension with human capital, human capital has positive effects on firms' performance.

The above findings suggest that consideration must be given to the evaluation of the real cost of counter-knowledge or inappropriate assumptions on human capital. This paper offers a model that integrates positive theoretical views of human capital on objective performance measures. In doing so, while data on counter-knowledge, RACAP and human capital, were collected through telephone interviews, we measured financial performance with objective data from the database (SABI). Findings from this study make an important contribution to the ongoing debate surrounding the 
relationship between human capital and financial performance, and reinforces the literature which claims that improvements in the development and management of human capital may lead to increased company benefits.

\section{Acknowledgements}

The data of this research were taken from a research programme supported by the Spanish Ministry of Education (REF: ECO2011-28,641-C02-02) and the Mobility Project (REF: PRX14/00164). 


\section{References}

Abeysekera, I. 2006. The project of intellectual capital disclosure: researching the research. Journal of Intellectual Capital, 7(1), 61-77.

Acquadro, C., Jambon, B., Ellis, D., \& Marquis, P. (1996). Language and translation issues. In B. Spilker (Ed.), Quality of life and pharmacoeconomics in clinical trials (2nd edition) (pp. 575-585). Philadelphia: Lippincott-Raven.

Anderson, J.C. \& Gerbing, D. (1988). Structural Modelling in Practice: A Review and Recommended Two-Steps Approach. Psychological Bulletin, 1033: 411-423.

Andriessen, D. (2006). On the metaphorical nature of intellectual capital: a textual analysis. Journal of Intellectual Capital, 7(1), 93-110.

Belkaoui, A.R. (2003). Intellectual capital and firm performance of US multinational firms: a study of the resource -based and stakeholder views. Journal of Intellectual Capital, 4(2), 215-226.

Bogdanowicz, M.S. \& Bailey, E.K. 2002. The value of knowledge and the values of the new knowledge worker: Generation $X$ in the new economy. Journal of European Industrial Training, 26(2/3/4), 125-129.

Bontis, N. (1998). Intellectual capital: an exploratory study that develops measures and models. Management Decision, 36(2), 63-76.

Bontis, N., Chua, W. and Richardson. S. (2000), Intellectual Capital and the Nature of Business in Malaysia. Journal of Intellectual Capital, 1(1), 85-100.

Bueno, E. (1998). Medición del capital intelectual: modelo Intelect. Instituto Universitario Euroforum Escorial, Madrid.

Cegarra, JG. Eldridge, S. Wensley, A. (2014). Counter-knowledge and realized absorptive capacity. European Management Journal, 32(1), 165-176.

Cepeda, G., Cegarra, J.G. \& Jimenez, D. (2012). The effect of absorptive capacity on innovativeness: Context and information systems capability as catalysts. British Journal of Management, 23(1), 110-129.

Chapman, J.A. \& Ferfolja, T. (2001). The acquisition of imperfect mental models and their use in hazardous situations. Journal of Intellectual Capital, 24, 398-409.

Chen, J., Zhu, Z. and Xie, H.Y. (2004). Measuring Intellectual Capital: A New Model and Empirical Study. Journal of Intellectual Capital, 5(1), 195-212.

Cheng, MY, Lin JY, Hsiao, TY, Lin, T W. (2010). Invested Resource, Intellectual Capital, and Corporate Performance. Journal of Intellectual Capital, 11(4), 433-455.

Chesbrough, H. W. (2003). 'The logic of open innovation: Managing intellectual property. California Management Review, 45, 33-58.

Churchill, G.A. (1979). A paradigm for developing better measures of marketing constructs. Journal of Marketing Research, 16, 64-73.

Cohen, W.M., D. Levinthal. 1990. Absorptive capacity: A new perspective on learning and innovation. Administrative Science Quarterly. 35 128-152. 
Darr, E., Argote, L. \& Epple, D. (1995). The acquisition, transfer and depreciation of knowledge in service organizations: Productivity in franchises. Management Science, 41(11), 1750-1762.

Dutton, J.E., Duberich, J.M. \& Harquail, C.V. (1994). Organizational Images and Member Identification. Adminitrative Science Quarterly, 39, 239-263.

Fernandez, V. \& Sune, A. (2009). Organizational forgetting and its causes: an empirical research. Journal of Organizational Change Management, 226, 620-634.

Fornell, C. \& Larcker, D.F. (1981). Evaluating structural equation models with unobservable variables and measurement error. Journal of Marketing Research, 181, 39-50.

Galbraith, J.K. (1969). The New Industrial State. Bost on: Houghton-Mifflin.

Gibb, A.A. (1997). Small Firms' Training and Competitiveness: Building Upon the Small Business as a Learning Organisation. International Small Business Journal, 15(3), 13-29.

Gray C. (2006). Absorptive capacity, knowledge management and innovation in entrepreneurial small firms. International Journal of Entrepreneurial Behaviour and Research, 12, 345-360.

Guillemin, F., Bombardier, C., \& Beaton, D. (1993). Cross-cultural adaptation of health-related quality of life measures: Literature review and proposed guidelines. Journal of Clinical Epidemiology, 46(12), 1417-1432.

Herholdt, J. 2004. Employment brand â€“ Four bottom lines and a couple of growth engines. In Boninelli, I. \& Meyer, T.N.A. (eds.). Building human capital: South African perspectives. Randburg: Knowres Publishing.

Jansen, J. J. P., F. A. J. Van Den Bosch and H. W. Volberda (2005). Managing potential and realized absorptive capacity: How do organizational antecedents matter?', Academy of Management Journal, 48, 99-1015.

Kim, L. (1998). Crisis construction and organizational learning: Capability building in catching-up at Hyundai Motor. Organization Science, 9, 506-521.

Kurland, N. \& Pelled, L. (2000). Passing the word: Toward a model of gossip and power in the workplace. The Academy of Management Review, 252, 428-438.

Labianca, G. \& Brass, D. (2006). Exploring the Social Ledger: Negative Relationships and Negative Asymmetry in Social Networks in Organizations. Academy of Management Review, 31(3), 596-614.

Lin, C.P. (2007). To share or not to share: Modeling knowledge sharing using exchange ideology as a moderator. Personnel Review, 36(3), 457-475.

Maditinos, D,. Chatzoudes.D,. Tsairidis.C., Theriou,G,.(2011). The impact of intellectual capital on firms' market value and financial performance. Journal of Intellectual Capital, 12(1), 132-151

Markoczy, L. (1994). Modes of organizational learning. International Studies of Management and Organization, 244, 5-30.

Mavridis, D.G., Kyrmizoglou, P. (2005). Intellectual capital performance drivers in the Greek banking sector. Management Research News, 28(5), 43-62. 
McDougall, P.P., Covin, J.G., Robinson, R.B. and Herron, L. (1994), The effects of industry growth and strategic breadth on new venture performance and strategy content. Strategic Management Journal, 15(7), 537-554.

Menon, A., Bharadwaj S.G., and Howell, R. (1996). The quality and effectiveness of marketing strategy: Effects of functional and dysfunctional conflict in intraorganizational relationships. Journal of the Academy of Marketing Science, 24, 299313.

Nahapiet, J., Ghoshal, S. (1998). Social Capital, Intellectual Capital, and the Organizational Advantage. Academy of Management Review, 23(2), 242-266.

Nelson, D.L., Quick, J.C., Hitt, M.A. \& Moesel, D. (1990). Politics, lack of career progress, and work/home conflict: Stress and strain for working women. Sex roles, 23(3/4), 169-185.

Noblet, J.P., Simon, E. \& Parent, R. (2011). Absorptive capacity: a proposed operationalization. Knowledge Management Research \& Practice, 9, 367-377.

Podsakoff, P.M., MacKenzie, S.M., Lee, J., \& Podsakoff, N.P. (2003). Common method variance in behavioral research: A critical review of the literature and recommended remedies. Journal of Applied Psychology, 88, 879-903.

Roth, K. and Ricks, D.A. (1994), Goal configuration in a global industry context. Strategic Management Journal, 15(2), 103-120.

Ruta, C.D. (2009). HR portal alignment for the creation and development of intellectual capital. International Journal of Human Resource Management, 20(3), 562-77.

Scandura, T.A. \& Lankau, M.J. (1997). Relationships of gender, family responsibility and flexible work hours to organizational commitment and job satisfaction. Journal of Organizational Behaviour, 18(4), 377-391.

Seligman, M.E., \& Maier, S.F. (1967). Failure to escape traumatic shock. Journal of Experimental Psychology: General, 74(1), 1-9.

Shane, S. \& Venkatraman, S. (2000). The promise of entrepreneurship as a field of research. Academy of Management Journal, 25, 217-226.

Starbuck, W.H. (1996). Unlearning ineffective or obsolete technologies. International Journal of Technology Management, 11(3), 725-737.

Steven H.A. \& Roy-Girard, D. (2007). Toxins in the workplace: affect on organizations and employees. Corporate Governance, 7(1), 17 - 28

Szvetelszky, Z. (2003). Ways and transformations of gossip. Journal of Cultural and Evolutionary Psychology, 12, 109-122.

Thompson, D. (2008). Counter-knowledge, Atlantic Books, London.

Unger, J. M., Rauch, A. \& Frese, M. (2011). Human capital and entrepreneurial success: A meta-analytical review. Journal of Business Venturing, 341-358.

Wall, A. (2007). The measurement and management of intellectual capital in the public sector. Public Management Review, 7(2), 289-303.

Weatherly, L.A. (2003). Human Capital - The Elusive Asset; Measuring and managing Human Capital. Alexandria: Society for Human Resource Management. 
Zahra, S. A. \& George, G. (2002). Absorptive capacity: A review, reconceptualization, and extension. Academy of Management Review, 27(2), 185-203.

Zhou, A.Z. \& Fink, D. (2003). The Intellectual capital web. A systematic linking of intellectual capital and knowledge management. Journal of Intellectual Capital, 4(1), $34-48$. 


\section{Appendix 1. Questionnaire items}

Counter-knowledge: ( $1=$ high disagreement and $7=$ high agreement $)$

CK1: There is gossip that thrives on lies, exaggerations and partial truths

CK2: There are malicious rumours which support mistrust

CK3: There are malicious stories about staff that often lead to misunderstandings

CK4: Organizational members share unverified information using technology tools

Source: Chapman \& Ferfolja (2001)

Potential Absorptive Capacity: (1= high disagreement and $7=$ high agreement):

PACAP1: Our unit has frequent interactions with corporate headquarters to acquire new knowledge

PACAP2: Employees of our unit regularly visit other branches

PACAP3: We collect industry information through informal means (e.g. lunch with industry friends, talks with trade partners).

PACAP4: Other divisions of our company are hardly visited (reversed).

PACAP5: Our unit periodically organises special meeting with customers or third parties to acquire new knowledge.

PACAP6: Employees regularly approach third parties such as accountants, consultants or tax consultants

PACAP7: We are slow to recognise shifts in our market (e.g. competition, regulation, demography) (reversed).

PACAP8: New opportunities to serve our clients are quickly understood

PACAP9: We quickly analyze and interpret changing market demands

(Source: Jansen et al, 2005)

Realised Absorptive Capacity: (1= high disagreement and 7= high agreement)

RACAP1: Our unit regularly considers the consequences of changing market demands in terms of new products and services

RACAP2: Employees record and store newly acquired knowledge for future reference

RACAP3: Our unit quickly recognises the usefulness of new external knowledge to existing knowledge

RACAP4: Employees hardly share practical experiences (reverse)

RACAP5: We laboriously grasp the opportunities for our unit from new external knowledge (reverse)

RACAP6: Our unit periodically meets to discuss consequences of market trends an new product development

RACAP7: Its clearly known how activities within our unit should be performed

RACAP8: Client complaints fall on deaf ears in our unit (reverse)

RACAP9: Our unit has a clear division of roles and responsibilities

RACAP10: We constantly consider how to better exploit knowledge

RACAP11: Our unit has difficulty implementing new products and services (reverse)

RACAP12: Employees have a common language regarding our products and services

(Source: Jansen et al, 2005)

Human Capital: with respect to their competitors indicate the degree in which your company reached the following objectives $(1=$ high disagreement and $7=$ high agreement):

HC1: Our company has employees more satisfied / motivated

HC2: Our company has a lower turnover

HC3: Our company has lower absenteeism

(Source: adapted from intellect model Bueno (1998)

Financial performance

FP1: ROI (Return on investments)

FP2: ROE (Return on Equity)

FP3: Profit Margin (Profitability)

(Source: from the SABI Database based on the statistical year 2009) 
Table 1. Construct summary, confirmatory factor analysis and scale reliability

\begin{tabular}{|c|c|c|c|}
\hline Construct & $\begin{array}{l}\text { Standardized } \\
\text { loading }\end{array}$ & t-value & $\begin{array}{c}\text { Reliability } \\
\left(\mathbf{S C R}^{\mathrm{a}} ., \mathbf{A V E}^{\mathbf{b}}\right)\end{array}$ \\
\hline \multicolumn{4}{|c|}{ Counter-knowledge (CK) } \\
\hline CK1 & 0.95 & 24.39 & $\mathrm{AVE}=0.74$ \\
\hline CK2 & 0.97 & 27.35 & $\mathrm{SCR}=0.94$ \\
\hline CK3 & 0.87 & 13.82 & \\
\hline CK4 & 0.72 & 7.24 & \\
\hline \multicolumn{4}{|c|}{ Absorptive Capacity (ACAP) } \\
\hline RACAP & 0.95 & 9.96 & $\mathrm{AVE}=0.80$ \\
\hline PACAP & 0.88 & 4.14 & $\mathrm{SCR}=0.95$ \\
\hline \multicolumn{4}{|c|}{ Human Capital (HC) } \\
\hline $\mathrm{HC} 1$ & 0.89 & 28.20 & $\mathrm{AVE}=0.53$ \\
\hline $\mathrm{HC} 2$ & 0.68 & 5.57 & $\mathrm{SCR}=0.71$ \\
\hline $\mathrm{HC} 3$ & 0.56 & 8.55 & \\
\hline \multicolumn{4}{|c|}{ Financial performance (FP) } \\
\hline FP1 & 0.57 & 2,89 & $\mathrm{AVE}=0.54$ \\
\hline FP2 & 0.89 & 3.39 & $\mathrm{SCR}=0.70$ \\
\hline FP3 & 0.65 & 3.67 & \\
\hline
\end{tabular}


Table 2. Descriptive Statistics and Discriminant Validity

\begin{tabular}{lllllllll}
\hline & Mean & SD & AVE & CR & 1 & $\mathbf{2}$ & $\mathbf{3}$ & $\mathbf{4}$ \\
\hline 1. Counterknowledge & 3.11 & 6.94 & 0.74 & 0.94 & $\mathbf{0 . 8 6}$ & & & \\
2. Absorptive Capacitiy & 4.94 & 1.07 & 0.80 & 0.95 & -0.24 & $\mathbf{0 . 8 9}$ & & \\
3. Human Capital & 4.61 & 1.41 & 0.53 & 0.71 & -0.31 & 0.46 & $\mathbf{0 . 7 3}$ & \\
4. Financial Performance & 0 & 1 & 0.54 & 0.70 & 0.10 & 0.03 & 0.02 & $\mathbf{0 . 7 3}$ \\
\hline
\end{tabular}

Notes: $n . a=$ not applicable because they are formative measures. Mean $=$ the average score for all of the items included in this measure; $\mathrm{SD}=$ Standard Deviation; AVE = Average Variance Extracted; the bold numbers on the diagonal are the square root of the Average

Variance Extracted, Shared Variances are given in the lower triangle of the matrix; CR = Composite Reliability. 
Table 3. Goodness-of-fit Measures Model

\begin{tabular}{|c|c|}
\hline & Model \\
\hline Degree of freedom & 50 \\
\hline Satorra-Bentler Chi-square & $56,76(\mathrm{p}=0.81)$ \\
\hline Goodness-of-Fit Index (GFI) & 0.93 \\
\hline Root Mean Square Residual (RMSR) & 0.02 \\
\hline Root Mean Square Error of Approximation (RMSEA) & 0.07 \\
\hline Adjusted Goodness-of-Fit Index (AGFI) & 0.89 \\
\hline Normed Fit Index (NFI) & 0.93 \\
\hline Comparative Fix Index (CFI) & 0.99 \\
\hline
\end{tabular}


Table 4. Summary of Results

\begin{tabular}{|l|c|c|c|c|}
\hline \multicolumn{1}{|c|}{ Model } & Hypotheses & $\begin{array}{c}\text { Supported/Non } \\
\text { supported }\end{array}$ & $\begin{array}{c}\text { Standardized } \\
\text { parameter } \\
\text { estimate }\end{array}$ & $\mathrm{R}^{2}$ \\
\hline$C K----->A C A P$ & $\mathrm{H}_{1}$ & Yes & $-.227^{* * *}$ & .05 \\
\hline$C K----->H C$ & $\mathrm{H}_{2}$ & Yes & $-.201^{* * *}$ & .36 \\
\hline$A C A P--->H C$ & $\mathrm{H}_{3}$ & Yes & $.521^{* * * *}$ & .36 \\
\hline$H C----->F P$ & $\mathrm{H}_{4}$ & Yes & $.275^{* *}$ & .07 \\
\hline
\end{tabular}

$* * * \mathrm{p}<0.001 ; * * \mathrm{p}<0.01$ 
Figure 1: Theoretical model

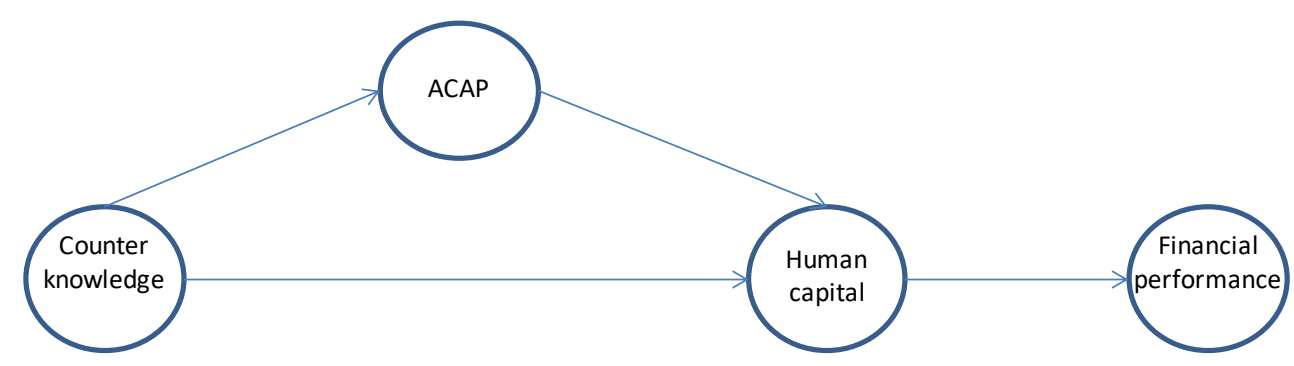

